\title{
COVID-19 pandemic challenges for International Medical Graduates (IMGs) practicing in the United States
}

\author{
Srikrishna Malayala ${ }^{1}$, Ramesh Adhiakri², Atul Bali ${ }^{3}$, and Ram Sanjeev Alur ${ }^{3}$ \\ ${ }^{1}$ Temple University \\ ${ }^{2}$ Franciscan Health Lafayette East \\ ${ }^{3}$ Affiliation not available
}

November 21, 2020

\begin{abstract}
Purpose: Given that nearly a quarter of the US physician workforce are international medical graduates (IMGs), many of whom remain on temporary work visas for prolonged periods due to processing delays, the pandemic has posed unique challenges to these frontline workers and has arbitrarily limited our physician workforce. Objective: The objective of the study is to understand the role of IMG physicians practicing in the US, their limitations and challenges due to immigration related issues. Methods: Using a cross-sectional survey across social media platforms, we obtained data from IMGs regarding their role in healthcare, to the impact of visa-related restrictions on their personal and professional lives. Results: A total of 2630 IMGs responded to the survey, Hospital Medicine $(1684,65.7 \%)$ being the predominant specialty encountered. $64.1 \%$ were practicing in Medically Underserved Areas (MUA) or Health Professional Shortage Areas (HPSA), with 45.6\% practicing in a rural area. Nearly $89 \%$ of respondents had been involved with direct care of COVID-19 patients, with $63.7 \%$ assuming administrative responsibilities for COVID-19 preparedness. 93\% physicians expressed inability to serve in COVID-19 surge areas due to visarelated restrictions. $72 \%$ physicians reported that their families would be at risk for deportation in case of their disability or death. Most respondents (98.8\%) felt that permanent resident status would help alleviate the above concerns. Conclusion: Easing immigration restrictions could prove significantly bolster the current physician workforce and prove beneficial in our response to the COVID-19 pandemic.
\end{abstract}

\section{Hosted file}

COVID-19 final paper, IJCP.pdf available at https://authorea.com/users/350517/articles/ 494342-covid-19-pandemic-challenges-for-international-medical-graduates-imgs-practicingin-the-united-states

\section{Hosted file}

Table 1 covid survey.pdf available at https://authorea.com/users/350517/articles/494342covid-19-pandemic-challenges-for-international-medical-graduates-imgs-practicing-in-theunited-states

\section{Hosted file}

Table 2 covid.pdf available at https://authorea.com/users/350517/articles/494342-covid-19pandemic-challenges-for-international-medical-graduates-imgs-practicing-in-the-unitedstates

\section{Hosted file}


Table 3 COVID.pdf available at https://authorea.com/users/350517/articles/494342-covid-19pandemic-challenges-for-international-medical-graduates-imgs-practicing-in-the-unitedstates 